\title{
Morphogenesis of infectious hepatitis C virus particles
}

\author{
Tetsuro Suzuki * \\ Department of Infectious Diseases, Hamamatsu University School of Medicine, Hamamatsu, Japan
}

\section{Edited by:}

Akio Adachi, The University of

Tokushima Graduate School, Japan

\section{Reviewed by:}

MinKyung Yi, University of Texas Medical Branch at Galveston, USA

Michael Schindler, Helmholtz Zentrum München - German Research Center for Environmental Health, Germany Hideki Tani, National Institute of Infectious Diseases, Japan

*Correspondence:

Tetsuro Suzuki, Department of Infectious Diseases, Hamamatsu

University School of Medicine, 1-20-1 Handayama, Higashi-ku, Hamamatsu 431-3192, Japan.

e-mail: tesuzuki@hama-med.ac.jp
More than 170 million individuals are currently infected with hepatitis $\mathrm{C}$ virus (HCV) worldwide and are at continuous risk of developing chronic liver disease. Since a cell culture system enabling relatively efficient propagation of HCV has become available, an increasing number of viral and host factors involved in HCV particle formation have been identified. Association of the viral Core, which forms the capsid with lipid droplets appears to be prerequisite for early HCV morphogenesis. Maturation and release of HCV particles is tightly linked to very-low-density lipoprotein biogenesis. Although expression of Core as well as E1 and E2 envelope proteins produces virus-like particles in heterologous expression systems, there is increasing evidence that non-structural viral proteins and p7 are also required for the production of infectious particles, suggesting that HCV genome replication and virion assembly are closely linked. Advances in our understanding of the various molecular mechanisms by which infectious HCV particles are formed are summarized.

Keywords: hepatitis C virus, assembly, lipid droplet, VLDL

\section{INTRODUCTION}

Hepatitis C virus (HCV) infection is a major cause of chronic hepatitis, liver cirrhosis, and hepatocellular carcinoma. HCV is primarily transmitted by blood-borne routes, including shared needles and transfused blood products. The WHO estimates that a minimum of $2-3 \%$ of the world's population is chronically infected with HCV (Wasley and Alter, 2000). Despite the fact that $\mathrm{HCV}$ is targeted by innate, cellular, and humoral immune mechanisms, it establishes long-standing persistent infection in a majority of the people that it infects (Pawlotsky, 2006). HCV belongs to the genus Hepacivirus within the Flaviviridae family. The virus forms small round-shaped particles ranging from 50 to $80 \mathrm{~nm}$ in diameter. The mature HCV virion is thought to consist of a nucleocapsid, an outer envelope composed of E1 and E2 viral proteins, and a lipid membrane. HCV particles isolated from the sera of infected patients demonstrate heterogeneity in their density. Density gradient analyses have shown that viral RNA exists within both low- and high-density fractions (Andre et al., 2005), and that the low-density fractions contain lipoproteins that associate with apolipoprotein $\mathrm{B}(\mathrm{ApoB})$, apolipoprotein $\mathrm{E}$ (ApoE), triglycerides, and cholesterol, as well as viral structural proteins (Thomssen et al., 1992; Andre et al., 2002; Maillard et al., 2006; Nielsen et al., 2006). Only the low-density fraction derived from HCV-positive human serum exhibits high infectivity in chimpanzees (Bradley et al., 1991; Beach et al., 1992). Since the establishment of a robust tissue culture infection system using strain HCV JFH-1 (Lindenbach et al., 2005; Wakita et al., 2005; Zhong et al., 2005), the entire HCV lifecycle has been studied and the biophysical properties of the viral particles produced using the HCVcc cell culture system have been characterized. Most viral RNA-containing particles secreted from HCV-infected cells are poorly infectious and fractionate at high densities such as $\sim 1.14 \mathrm{~g} / \mathrm{mL}$, while highly infectious HCVcc are found within low-density fractions of $\sim 1.10 \mathrm{~g} / \mathrm{mL}$ (Lindenbach et al., 2005).
Here, we provide a general account of our current understanding of the HCV lifecycle and a review of recent studies focusing on the morphogenesis of $\mathrm{HCV}$ particles within cell culture systems.

\section{HCV GENOME ORGANIZATION AND PROTEIN SYNTHESIS}

Hepatitis $\mathrm{C}$ virus is a positive-stranded RNA virus, and its $\sim 9.6-\mathrm{kb}$ genome contains an open reading frame encoding a polyprotein of $\sim 3000$ amino acids (aa) flanked by untranslated regions (UTRs) at both ends. Six genotypes have been reported based on HCV genome sequence variations (Simmonds, 1996). The UTRs are highly structured sequences encompassing critical cis-active RNA elements essential for genome replication and translation. The 5' UTR, which is 341 nucleotides (nt) in length, contains an internal ribosomal entry site, which is a prerequisite for cap-independent translation of viral RNA, from which four highly structured domains (I-IV) are produced (Bukh et al., 1992; Tsukiyama-Kohara et al., 1992; Wang et al., 1993; Honda et al., 1996; Friebe et al., 2001). The 3' UTR varies between 200 and $235 \mathrm{nt}$ in length, including a short variable region, as well as a poly(U/UC) tract with an average length of $80 \mathrm{nt}$ which is considered crucial for RNA replication, and a virtually invariant 98 -nt X-tail region (Tanaka et al., 1995; Ito and Lai, 1999; Friebe and Bartenschlager, 2002; Yi and Lemon, 2003).

The genome is translated into a single precursor polyprotein, which is processed by cellular and viral proteases into 10 structural and non-structural proteins (Core, E1, E2, p7, NS2, NS3, NS4A, NS4B, NS5A, and NS5B; Figure 1). HCV proteins derived from the amino-terminal third of the precursor include Core, E1 and E2 structural proteins. A crucial function of Core protein is assembly of the viral nucleocapsid. The aa sequence of this protein is well conserved among different HCV strains compared to other HCV proteins. The non-structural (NS) proteins NS3-NS5B are thought to assemble into a membrane-associated HCV RNA replicase complex. NS3 functions as serine protease, RNA helicase, and NTPase. 


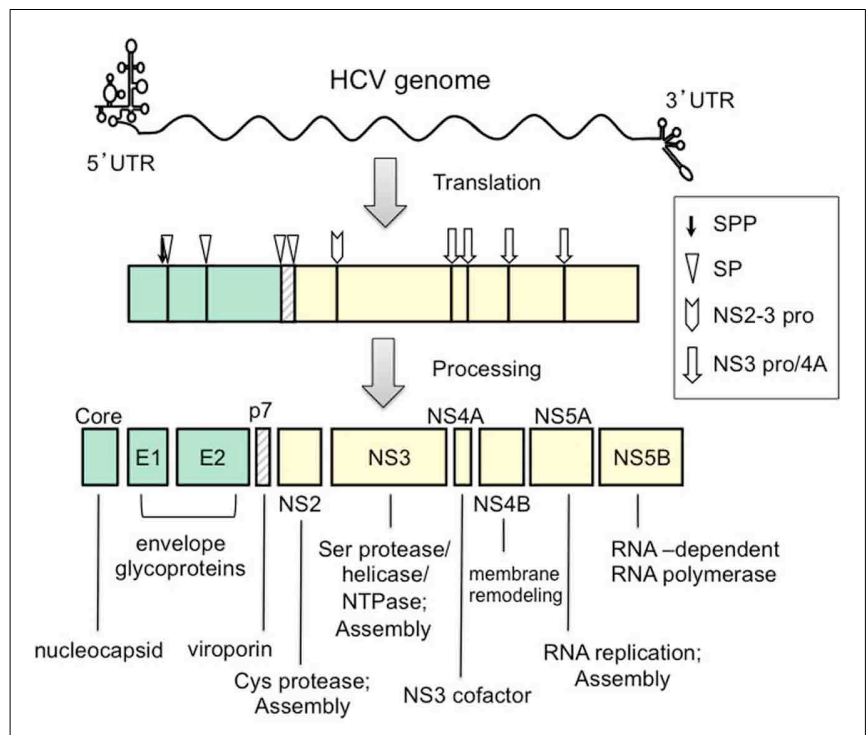

FIGURE 1 | The HCV genome and polyprotein. The RNA genome comprises a 9.6-kb RNA of plus strand polarity. Post-translational cleavages by SPP (signal peptide peptidase), SP (signal peptidase), NS2-3 pro (NS2-NS3 cysteine protease), and NS3 pro/4A (NS3 serine protease and NS4A complex) lead to the production of functional HCV proteins.

Functions of each protein in the viral lifecycle are indicated below the open reading frame.

NS4A serves as a cofactor for NS3 and is involved in targeting NS3 to the ER membrane (Wolk et al., 2000). NS4B plays a role in the remodeling of host-cell membranes, probably to generate a site for replicase assembly. NS5A is also thought to play an important but undefined role in viral RNA replication. NS5B functions as an RNA-dependent RNA polymerase. The role of HCV NS proteins in assembly of the infectious virion is described below.

\section{CORE PROTEIN AND NUCLEOCAPSID FORMATION}

The Core is 191 aa in length and consists of three distinct predicted domains: an N-terminal domain that is two-thirds hydrophilic, a C-terminal domain that is one-third hydrophobic, and a short signal peptide sequence of the downstream protein E1. The precursor Core is cleaved between Core and E1 by a host signal peptidase. A C-terminal membrane-anchor of the Core is further cleaved by a signal peptide peptidase. The mature Core is estimated to be 177-179 aa (Ogino et al., 2004; Okamoto et al., 2004). Maturation of the Core by a signal peptide peptidase is required for virion production (Okamoto et al., 2008; Targett-Adams et al., 2008). Biophysical techniques have been used to demonstrate that the mature Core is a dimeric alpha-helical protein (Boulant et al., 2005). Its aa sequence is highly conserved among different HCV strains, compared with other HCV proteins. Thus, Core is used in most serologic assays since anti-core antibodies are highly prevalent among $\mathrm{HCV}$-infected individuals.

Core has been detected in a number of subcellular compartments. Core protein is found on ER membranes, on the surface of lipid droplets (LDs), on the mitochondrial outer membrane, and to some extent, in the nucleus (Moradpour et al., 1996; Barba et al., 1997; Moriya et al., 1998; Yasui et al., 1998; Hope et al.,
2002; Suzuki et al., 2005). Following is a proposed mechanism of translocation of Core to membranes within the ER network such as LDs (McLauchlan et al., 2002; Schwer et al., 2004). After being processed by a signal peptide peptidase, a large part of the Core remains within cytoplasmic leaflets of the ER membrane due to preservation of the original transmembrane domain. The cytoplasmic leaflets then swell as lipid accumulates between the two membrane leaflets. As a result, the Core is translocated along with part of the ER membrane to the surface of a nascent LD before the droplet buds off the ER. The proteasome-dependent degradation pathway then participates in post-translational modification of the Core (Suzuki et al., 2001, 2009; Moriishi et al., 2003, 2007, 2010; Shirakura et al., 2007). Ubiquitin ligase E6AP and proteasome activator PA28gamma are key regulators in determining the fate of the Core, and thereby play a role in virus production (Shirakura et al., 2007; Moriishi et al., 2010).

The $\sim 120 \mathrm{~N}$-terminal residues of the Core protein (domain I) contain multiple positively charged residues that are implicated in RNA binding and homo-oligomerization. It is therefore likely that this domain is a prerequisite for assembly of the HCV nucleocapsid (Kunkel et al., 2001; Klein et al., 2004, 2005; Majeau et al., 2004). It has been shown that a region extending from aa 72 to 91 is responsible for auto-oligomerization of Core (Nakai et al., 2006). Although conclusive data for direct packaging of the HCV genome into the viral capsid is lacking, the viral RNA sequence of the Core protein through to the NS2 region appears not to contain a cisacting packaging signal. A subgenomic replicon RNA carrying the NS3-NS5B region can be encapsidated in the viral trans-packaging system (Ishii et al., 2008; Steinmann et al., 2008; Adair et al., 2009; Masaki et al., 2010). In addition, the RNA sequence encoding the first 62 aa of Core contains highly conserved structures including two stem-loops that are important for RNA translation/replication (McMullan et al., 2007). Domain II (aa 120-170) is predicted to form two alpha-helices that enable Core to associate with membrane proteins and lipids. Domain II is involved in targeting of Core to LDs. It has been proposed that domain II folding occurs in a membrane environment and is critical for the folding of domain I (Boulant et al., 2005). In addition, a cysteine residue at aa 128 of domain II creates a disulfide bond to produce a Core protein dimer that is required for particle formation (Kushima et al., 2010). Domain III, pertaining to $\sim 20$ residues at the C-terminal, is highly hydrophobic and serves as a signal sequence for E1. Although little is known about the molecular mechanisms governing assembly of Core into nucleocapsids, comprehensive mutagenesis studies have enabled identification of various aa residues which are essential for HCV morphogenesis (Murray et al., 2007; Alsaleh et al., 2010; Kopp et al., 2010).

\section{INVOLVEMENT OF OTHER HCV PROTEINS IN ASSEMBLY}

Two N-glycosylated envelope proteins E1 and E2 are exposed on the surface of the virus as a heterodimer that mediates viral attachment to host-cell receptors and facilitates virus entry (Op De Beeck et al., 2004; Vieyres et al., 2010). During their synthesis, E1 and E2 assemble as non-covalent heterodimers. Ectodomains of E1 and E2 are translocated inside the ER lumen and their transmembrane domains are inserted in the membrane of this compartment. E1 contains four to five N-linked glycans and E2 
has $11 \mathrm{~N}$-glycosylation sites. HCV glycans, which are thought to contain a mixture of complex and high mannose side-chain, play a role in envelope protein folding and formation of the E1/E2 complexes. The importance of incorporating $\mathrm{N}$-linked glycans of the envelope proteins into infectious virions has been demonstrated (Helle et al., 2010). A recent study has shown that HCV infection activates the ER-associated degradation pathway, which in turn controls the fate of E1 and E2 and modulates virus production (Saeed et al., 2011).

A role of viral NS proteins in $\mathrm{HCV}$ production was first suggested following the observation that JFH-1-derived NS proteins are required to generate infectious virus from intra- and inter-genotype chimeric constructs (Lindenbach et al., 2005; Pietschmann et al., 2006). Evidence supporting a role of NS2, NS3, and NS5A in the assembly or release of infectious HCV has come from mutational analyses (Jones et al., 2007; Miyanari et al., 2007; Appel et al., 2008; Jirasko et al., 2008; Ma et al., 2008; Masaki et al., 2008; Tellinghuisen et al., 2008).

NS5A is a hydrophilic phosphoprotein which plays a key role in viral RNA replication and is involved in modulation of cell signaling pathways and the interferon response (Huang et al., 2007). NS5A is associated with membrane mediated by a unique amphipathic alpha helix which is located at its N-terminus (Moradpour et al., 2005), and part of NS5A localizes to LDs when expressed alone or as the viral polyprotein (Shi et al., 2002). Experiments based on HCV genomes containing mutated NS5A have shown that some mutants result in failure of association of NS5A with LDs and failure of production of infectious particles (Miyanari et al., 2007). Further studies have revealed that the C-terminal region of NS5A plays a key role in HCV production (Appel et al., 2008; Masaki et al., 2008; Tellinghuisen et al., 2008). Substitutions at a serine cluster of the NS5A C-terminus (aa 2428, 2430, and 2433) which have no impact on viral RNA replication, have been observed to inhibit the interaction between NS5A and Core, thereby suggesting that an association between NS5A and Core might be involved in virus production (Masaki et al., 2008). Structural analyses have shown that the N-terminal region of NS5A forms a "claw-like" dimer, which might accommodate RNA and interact with viral and cellular proteins and membranes (Huang et al., 2005; Tellinghuisen et al., 2005). It appears that recruitment of NS5A to LDs, thereby enabling interaction with the Core, is crucial for virion assembly. One can imagine that newly synthesized HCV RNA bound to NS5A is released from the replication complex-containing membrane compartment and can then be captured by Core through interaction with the C-terminal region of NS5A at the surface of LDs or LD-associated membranes. Consequently, viral RNA becomes encapsidated and virion assembly proceeds (Figure 2). In this regard, a study has revealed an interaction between NS5A and ApoE, suggesting that recruitment of ApoE by NS5A is important for the assembly and release of $\mathrm{HCV}$ particles (Benga et al., 2010).

NS3-NS4A is another component of the viral replication complex that exhibits serine protease, as well as RNA helicase and RNA-stimulated NTPase activity, necessary for viral RNA replication. It is now apparent that NS3-NS4A also contributes to viral assembly (Yi et al., 2007; Ma et al., 2008; Han et al., 2009; Phan et al., 2011). A previous study has provided genetic evidence that

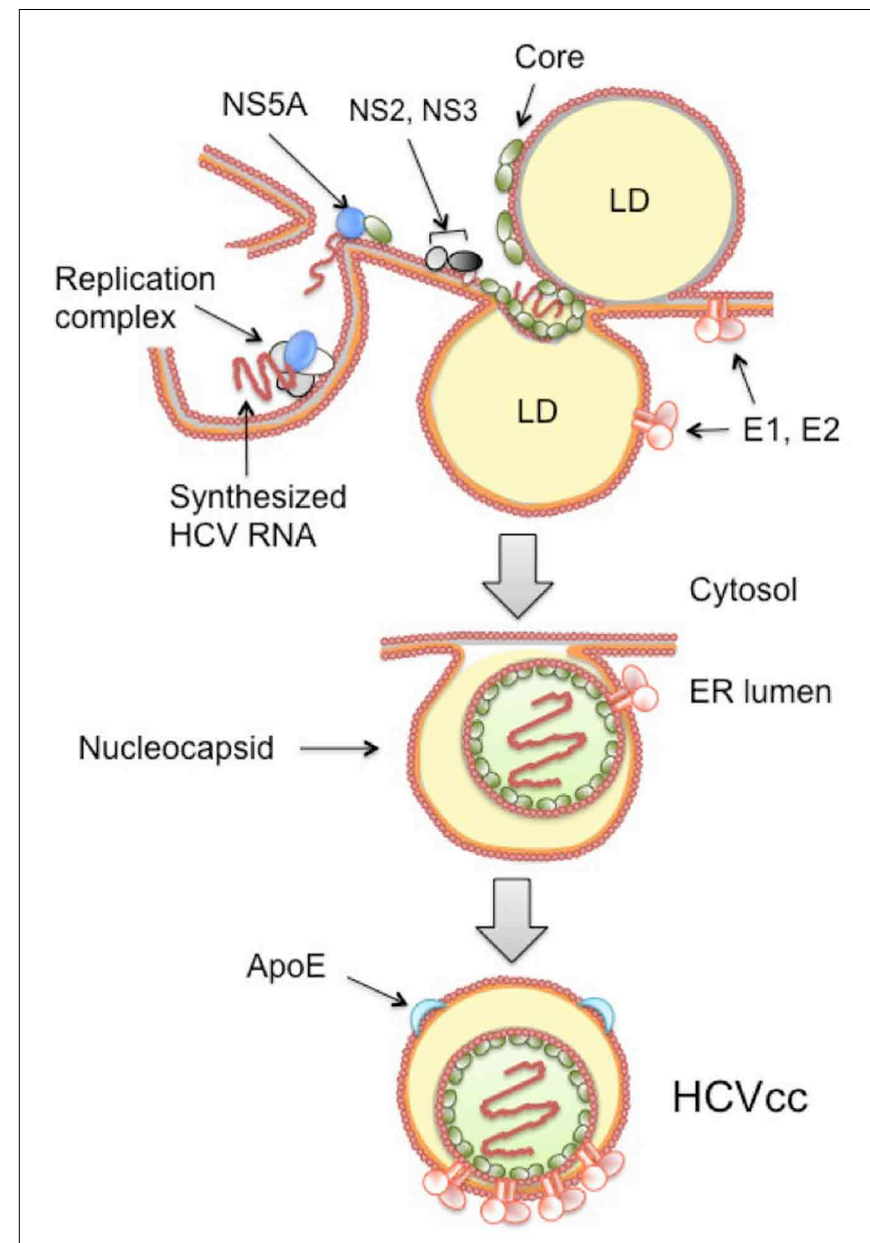

FIGURE 2 | Proposed model for assembly of HCV particles. After accumulation of synthesized genome RNA and the viral proteins, the HCV particles are assembled in an ER-related compartment in close connection with the VLDL pathway. The viral replication complex, which is composed of NS3-NS5B and host factors, is a specialized structure protected by cellular membrane. Newly synthesized viral RNAs are recruited to surfaces of lipid droplet (LD), where ER membrane is associated, possibly via interaction between NS5A and Core. Thus, the RNAs enable to associate with Core, thereby proceeding encapsidation and nucleocapsid formation. The nucleocapsid is presumably inserted into the lipid core of the luminal LD and buds into the ER lumen with incorporation of E1 and E2.

$\mathrm{HCV}$-lipoprotein particle formed is then released from the cells.

two major subdomains of the NS3 helicase, one demonstrating NTPase activity and the other associated with RNA binding, are involved in the early stages of virion assembly, independent of their roles as enzymes (Ma et al., 2008). A separate investigation has revealed a contribution of the acidic domain of NS4A to both RNA replication and virus assembly (Phan et al., 2011).

NS2 is a cysteine protease composed of a highly hydrophobic N-terminal membrane binding domain which forms either three or four transmembrane helices that insert into the ER membrane. NS2 also contains a C-terminal globular and cytosolic protease subdomain, that produce zinc-stimulated NS2/3 autoprotease activity together with the N-terminal one-third of NS3. 
Mutagenesis of NS2 has identified regions or residues that are important for infectious virus production (Jones et al., 2007; Yi et al., 2007, 2009; Jirasko et al., 2008, 2010; Dentzer et al., 2009; Phan et al., 2009; Ma et al., 2011; Popescu et al., 2011). For example, mutations involving the dimer interface of the protease region or the C-terminus of NS2 impair the production of infectious $\mathrm{HCV}$, while the catalytic activity of NS2 is not required for viral assembly. Genetic and biochemical data demonstrate that NS2 is possibly involved in multiple interactions with both HCV structural and NS proteins including E1-E2, p7, NS3, and NS5A, suggesting that NS2 has a role in recruiting these viral proteins to sites in close proximity with LDs. Alternatively, it may act as a scaffold promoting virus assembly (Jirasko et al., 2010; Ma et al., 2011; Stapleford and Lindenbach, 2011).

p7 is a 63-aa polypeptide located between E2 and NS2, and is a membrane-spanning protein localized within the ER. p7 belongs to a class of viral permeability-altering proteins termed "viroporins." It behaves as an ion channel when reconstituted into artificial lipid membranes. Although p7 is not required for viral RNA replication in cell culture, the protein is essential for HCV infectivity in chimpanzees (Sakai et al., 2003). Subsequent analyses in HCVcc systems have demonstrated that $\mathrm{p} 7$ is important for virion production since the introduction of $\mathrm{p} 7$ mutations, such as mutations in the basic residues required for its ion channel activity, impair virus production (Jones et al., 2007; Steinmann et al., 2007; Brohm et al., 2009). Although it is not yet clear whether the ion channel function of the protein is needed for virus assembly, a recent study has demonstrated that p7 functions as an $\mathrm{H}^{+}$ channel in native intracellular membranes and links p7-induced $\mathrm{pH}$ changes to the production of infectious intracellular virions (Wozniak et al., 2010).

\section{ROLE OF LIPID METABOLISM IN HCV ASSEMBLY}

$\mathrm{HCV} c \mathrm{c}$ contained within low-density fractions from the culture supernatant of virus-producing cells displays greater specific infectivity than virus in high-density fractions (Lindenbach et al., 2005; Ogawa et al., 2009). Looking also at the behavior of HCV circulating within the sera of infected hosts, it may be that lowdensity virus associates with lipid and very-low-density lipoprotein (VLDL) and/or low-density lipoprotein (LDL). Furthermore, HCV particles obtained from virus-infected animals, such as chimpanzees and chimeric mice transplanted with human hepatocytes, demonstrate greater infectivity than virus produced in cell cultures. The virus populations derived from these infected animals have been observed to fractionate into lower density fractions than a major population of HCVcc (Lindenbach et al., 2006). Interestingly, the association of cholesterol and sphingolipid with HCV virions has been shown to play a critical role in viral infectivity (Kapadia et al., 2007; Aizaki et al., 2008; Voisset et al., 2008). Depletion of cholesterol and sphingomyelin from HCV virions inhibits the infectivity of HCVcc (Aizaki et al., 2008). The structural requirement of virion-associated cholesterol for infectivity, as well as its influence on buoyant density, and the association of apolipoprotein with $\mathrm{HCV}$, has been further demonstrated by Yamamoto et al. (2011).

There is accumulating evidence that assembly and secretion of HCV particles are associated with the VLDL assembly pathway.
Lipoproteins can be differentiated on the basis of their density, which is affected by lipid content and the types of apolipoprotein they contain. VLDLs are large triglyceride-rich lipoproteins (30-80 $\mathrm{nm}$ in diameter) containing cholesterol, cholesteryl esters, ApoB, and other minor apolipoprotein(s). VLDLs carry triglyceride from the liver to peripheral tissue for storage and to provide a source of energy. Triglyceride availability and the size of intracellular triglyceride pools are important regulatory factors in the regulation of VLDL production. In addition, the microsomal triglyceride transfer protein (MTP), which is responsible for the transport of triglyceride and cholesteryl esters across ER membranes, is required for VLDL assembly. Purified membrane vesicles containing the HCV replication complex are enriched with ApoB, MTP, and ApoE (Huang et al., 2007). Moreover, agents that inhibit VLDL assembly also inhibit HCV secretion from cells producing infectious virus (Chang et al., 2007; Huang et al., 2007; Gastaminza et al., 2008). ApoB, ApoC1, and ApoE have been observed to associate with $\mathrm{HCV}$ particles during viral morphogenesis in the HCVcc system (Chang et al., 2007; Meunier et al., 2008; Jiang and Luo, 2009; Owen et al., 2009; Benga et al., 2010). Furthermore, ApoE depletion suppresses the production of infectious HCV (Chang et al., 2007; Jiang and Luo, 2009; Owen et al., 2009; Benga et al., 2010; Hishiki et al., 2010). These findings demonstrate that ApoE is important for HCV infectivity, suggesting that HCV virions are assembled as ApoE-enriched lipoprotein particles. A study in which virion-associated cholesterol was depleted and replenished with exogenous sterol analogs has provided evidence that virionassociated cholesterol contributes to the interaction between $\mathrm{HCV}$ and ApoE (Yamamoto et al., 2011). ApoE is a polymorphic protein with three major isoforms: ApoE2, ApoE3, and ApoE4. Differential roles of ApoE isoforms on infectious $\mathrm{HCV}$ production have been revealed: ectopic expression of ApoE3 or ApoE4 enables recovery of infectious HCV, while ApoE2 has little influence on virus production (Hishiki et al., 2010). Not surprisingly, ApoE2 demonstrates significantly less LDL receptor binding activity than ApoE3 and ApoE4 (Davignon et al., 1988).

Hepatitis $C$ virus may utilize the assembly and secretion of VLDL to exit cells. In fact, secretion of E1 and E2 within the culture supernatant is reduced by treatment with MTP inhibitors (Icard et al., 2009). VLDL maturation occurs by acquisition of lipids from LDs either in the ER lumen or in the Golgi apparatus. It is likely that HCV envelopment takes place in a lipid-enriched microdomain at the ER membrane where luminal LDs or VLDL precursors are generated (Figure 2), in keeping with evidence of increased cholesterol content among HCV particles compared to host-cell membranes (Aizaki et al., 2008).

Neutral lipids such as triglycerides and cholesterol esters are stored within cytosolic LD in cells. LD is thought to be a source of neutral lipid for metabolism and membrane synthesis. Neutral lipids form the LD core and are surrounded by an outer layer of amphipathic lipids such as phospholipids and cholesterol. LD is thought to be surrounded by a lipid monolayer. Prior to the availability of a tissue culture system for virion production, HCV Core was shown to associate with ER membranes and on the surface of LDs in heterologous expression systems in mammalian cells (Moradpour et al., 1996; Barba et al., 1997). Early studies of cells infected with HCV JFH-1 indicate that Core is detectable at the ER 
and on the surface of LDs in association with the ER (Rouille et al., 2006). Core associates with LDs in a time-dependent manner and disruption of this process coincides with a loss of virion production (Boulant et al., 2007). It has subsequently been demonstrated that LDs are directly involved in the production of infectious HCV and that Core recruits viral non-structural proteins as well as the replication complex to the $\mathrm{LD}$-associated membranes, suggesting that the association between Core and LDs is required at a certain stage of HCV morphogenesis (Miyanari et al., 2007). Fluorescent labeling and functional imaging of Core in living cells has recently been used to visualize Core during HCV assembly (Counihan et al., 2011). Core has been observed to move to the surface of large, immobile LDs soon after protein translation. Core has also been observed in motile puncta that travel along microtubules. Diacylglycerol acyltransferases (DGATs) catalyze the final step of triglyceride synthesis and are crucial for LD biogenesis. A study has revealed that DGAT1 interacts with Core and is required for trafficking of the Core to LD. Disrupting translocation of the Core to LD by inhibiting DGAT1 activity or through knockdown of the DGAT1 gene impairs virus production (Herker et al., 2010). Thus, there is now increasing evidence that LDs play a central role in the production of infectious HCV and participate in virus assembly. However, one study has demonstrated that, while Core derived from HCV JFH-1 is strongly associated with cytoplasmic LDs, minimal Core from a HCV clone with higher assembly efficiency is detectable on LDs (Shavinskaya et al., 2007). Thus, it remains debatable whether HCV assembly is initiated on the surface of LDs or at sites where ER cisternae are in contact with LDs. Based on the current evidence, a model for nucleocapsid formation following the initial phase of assembly is demonstrated in Figure 2. Two potential models to explain HCV nucleocapsid formation,

\section{REFERENCES}

Adair, R., Patel, A. H., Corless, L., Griffin, S., Rowlands, D. J., and Mccormick, C. J. (2009). Expression of hepatitis $\mathrm{C}$ virus (HCV) structural proteins in trans facilitates encapsidation and transmission of HCV subgenomic RNA. J. Gen. Virol. 90, 833-842.

Aizaki, H., Morikawa, K., Fukasawa, M., Hara, H., Inoue, Y., Tani, H., Saito, K., Nishijima, M., Hanada, K., Matsuura, Y., Lai, M. M. C., Miyamura, T., Wakita, T., and Suzuki, T. (2008). Critical role of virionassociated cholesterol and sphingolipid in hepatitis $\mathrm{C}$ virus infection. J. Virol. 82, 5715-5724.

Alsaleh, K., Delavalle, P.-Y., Pillez, A., Duverlie, G., Descamps, V., Rouille, Y., Dubuisson, J., and Wychowski, C. (2010). Identification of basic amino acids at the $\mathrm{N}$-terminal end of the core protein that are crucial for hepatitis $\mathrm{C}$ virus infectivity. J. Virol. 84, 12515-12528.

Andre, P., Komurian-Pradel, F., Deforges, S., Perret, M., Berland, J. L., Sodoyer, M., Pol, S., Brechot, C., Paranhos-Baccala, G., and Lotteau,

including the model shown in Figure 2, have been proposed by Bartenschlager et al. (2011).

\section{FUTURE PERSPECTIVES}

Evidence regarding the assembly of infectious HCV particles has accumulated over the past several years since the availability of HCV cc systems. A variety of key factors in HCV morphogenesis have been identified, including the requirement for components of the VLDL biosynthetic machinery and viral NS proteins. However, there are still essential questions to be answered. Detailed mechanisms pertaining to nucleotide formation, genome packaging, and the way in which HCV interacts with the lipoprotein/VLDL pathway, as well as the precise role of various NS proteins and p7 in $\mathrm{HCV}$ assembly, remain unclear. Structural studies will be important to clarify the exact composition of the HCV virion, as well as similarities and differences between HCVcc generated in Huh7-derived cells and the "lipoviroparticles" produced by circulating virus within infected individuals.

\section{ACKNOWLEDGMENTS}

The author is grateful to Masayoshi Fukasawa (National Institute of Infectious Diseases, Department of Biochemistry and Cell Biology) for his helpful discussion. The author would also like to thank all members of the National Institute of Infectious Diseases, Department of Virology II, as well as the Hamamatsu University School of Medicine, Department of Infectious Diseases, for their technical support and valuable discussion and advice. This work was supported in part by a Grant-in-Aid from the Ministry of Health, Labor, and Welfare of Japan, and by a Grant-in-Aid from the Ministry of Education, Culture, Sports, Science, and Technology of Japan.

infectious hepatitis $C$ virus particles. Trends Microbiol. 19, 95-103.

V. (2002). Characterization of lowand very-low-density hepatitis $\mathrm{C}$ virus RNA-containing particles. $J$. Virol. 76, 6919-6928.

Andre, P., Perlemuter, G., Budkowska, A., Brechot, C., and Lotteau, V. (2005). Hepatitis C virus particles and lipoprotein metabolism. Semin. Liver Dis. 25, 93-104.

Appel, N., Zayas, M., Miller, S., Krijnse-Locker, J., Schaller, T., Friebe, P., Kallis, S., Engel, U., and Bartenschlager, R. (2008). Essential role of domain III of nonstructural protein $5 \mathrm{~A}$ for hepatitis $\mathrm{C}$ virus infectious particle assembly. PLoS Pathog. 4, e1000035. doi:10.1371/journal.ppat.1000035

Barba, G., Harper, F., Harada, T., Kohara, M., Goulinet, S., Matsuura, Y., Eder, G., Schaff, Z., Chapman, M. J., Miyamura, T., and Brechot, C. (1997). Hepatitis C virus core protein shows a cytoplasmic localization and associates to cellular lipid storage droplets. Proc. Natl. Acad. Sci. U.S.A. 94, 1200-1205.

Bartenschlager, R., Penin, F., Lohmann, V., and Andre, P. (2011). Assembly of
Beach, M. J., Meeks, E. L., Mimms, L. T., Vallari, D., Ducharme, L., Spelbring, J., Taskar, S., Schleicher, J. B., Krawczynski, K., and Bradley, D. W. (1992). Temporal relationships of hepatitis C virus RNA and antibody responses following experimental infection of chimpanzees. $J$. Med. Virol. 36, 226-237.

Benga, W. J. A., Krieger, S. E., Dimitrova, M., Zeisel, M. B., Parnot, M., Lupberger, J., Hildt, E., Luo, G., Mclauchlan, J., Baumert, T. F., and Schuster, C. (2010). Apolipoprotein $\mathrm{E}$ interacts with hepatitis $\mathrm{C}$ virus nonstructural protein $5 \mathrm{~A}$ and determines assembly of infectious particles. Hepatology 51, 43-53.

Boulant, S., Targett-Adams, P., and Mclauchlan, J. (2007). Disrupting the association of hepatitis $C$ virus core protein with lipid droplets correlates with a loss in production of infectious virus. J. Gen. Virol. 88, 2204-2213.

Boulant, S., Vanbelle, C., Ebel, C., Penin, F., and Lavergne, J.-P. (2005).
Hepatitis C virus core protein is a dimeric alpha-helical protein exhibiting membrane protein features. J. Virol. 79, 11353-11365.

Bradley, D., Mccaustland, K., Krawczynski, K., Spelbring, J., Humphrey, C., and Cook, E. H. (1991). Hepatitis $C$ virus: buoyant density of the factor VIII-derived isolate in sucrose. $J$ Med. Virol. 34, 206-208.

Brohm, C., Steinmann, E., Friesland, M., Lorenz, I. C., Patel, A., Penin, F., Bartenschlager, R., and Pietschmann, T. (2009). Characterization of determinants important for hepatitis $\mathrm{C}$ virus $\mathrm{p} 7$ function in morphogenesis by using trans-complementation. J. Virol. 83, 11682-11693.

Bukh, J., Purcell, R. H., and Miller, R. H. (1992). Sequence analysis of the 5 ' noncoding region of hepatitis $\mathrm{C}$ virus. Proc. Natl. Acad. Sci. U.S.A. 89, 4942-4946.

Chang, K.-S., Jiang, J., Cai, Z., and Luo, G. (2007). Human apolipoprotein e is required for infectivity and production of hepatitis $\mathrm{C}$ virus in cell culture. J. Virol. 81, 13783-13793. 
Counihan, N. A., Rawlinson, S. M., and Lindenbach, B. D. (2011). Trafficking of hepatitis $\mathrm{C}$ virus core protein during virus particle assembly. PLoS Pathog. 7, e1002302. doi:10.1371/journal.ppat.1002302

Davignon, J., Gregg, R. E., and Sing, C. F. (1988). Apolipoprotein E polymorphism and atherosclerosis. Arteriosclerosis $8,1-21$.

Dentzer, T. G., Lorenz, I. C., Evans, M. J., and Rice, C. M. (2009). Determinants of the hepatitis $\mathrm{C}$ virus nonstructural protein 2 protease domain required for production of infectious virus. J. Virol. 83, 12702-12713.

Friebe, P., and Bartenschlager, R. (2002). Genetic analysis of sequences in the 3' nontranslated region of hepatitis $\mathrm{C}$ virus that are important for RNA replication. J. Virol. 76, 5326-5338.

Friebe, P., Lohmann, V., Krieger, N., and Bartenschlager, R. (2001). Sequences in the 5 ' nontranslated region of hepatitis $\mathrm{C}$ virus required for RNA replication. J. Virol. 75, 12047-12057.

Gastaminza, P., Cheng, G., Wieland, S., Zhong, J., Liao, W., and Chisari, F. V. (2008). Cellular determinants of hepatitis $\mathrm{C}$ virus assembly, maturation, degradation, and secretion. J. Virol. 82, 2120-2129.

Han, Q., Xu, C., Wu, C., Zhu, W., Yang, R., and Chen, X. (2009). Compensatory mutations in NS3 and NS5A proteins enhance the virus production capability of hepatitis $\mathrm{C}$ reporter virus. Virus Res. 145, 63-73.

Helle, F., Vieyres, G., Elkrief, L., Popescu, C.-I., Wychowski, C., Descamps, V., Castelain, S., Roingeard, P., Duverlie, G., and Dubuisson, J. (2010). Role of $\mathrm{N}$-linked glycans in the functions of hepatitis $\mathrm{C}$ virus envelope proteins incorporated into infectious virions. J. Virol. 84, 11905-11915.

Herker, E., Harris, C., Hernandez, C., Carpentier, A., Kaehlcke, K., Rosenberg, A. R., Farese, R. V. Jr., and Ott, M. (2010). Efficient hepatitis C virus particle formation requires diacylglycerol acyltransferase-1. Nat. Med. $16,1295-1298$

Hishiki, T., Shimizu, Y., Tobita, R., Sugiyama, K., Ogawa, K., Funami, K., Ohsaki, Y., Fujimoto, T., Takaku, H., Wakita, T., Baumert, T. F., Miyanari, Y., and Shimotohno, K. (2010). Infectivity of hepatitis C virus is influenced by association with apolipoprotein $\mathrm{E}$ isoforms. J. Virol. 84, 12048-12057.

Honda, M., Brown, E. A., and Lemon, S. M. (1996). Stability of a stem-loop involving the initiator AUG controls the efficiency of internal initiation of translation on hepatitis $\mathrm{C}$ virus RNA. RNA 2, 955-968.

Hope, R. G., Murphy, D. J., and Mclauchlan, J. (2002). The domains required to direct core proteins of hepatitis $C$ virus and GB virus-B to lipid droplets share common features with plant oleosin proteins. $J$. Biol. Chem. 277, 4261-4270.

Huang, H., Sun, F., Owen, D. M., Li, W., Chen, Y., Gale, M. Jr., and Ye, J. (2007). Hepatitis C virus production by human hepatocytes dependent on assembly and secretion of very low-density lipoproteins. Proc. Natl. Acad. Sci. U.S.A. 104, 5848-5853.

Huang, L., Hwang, J., Sharma, S. D., Hargittai, M. R. S., Chen, Y., Arnold, J. J., Raney, K. D., and Cameron, C. E. (2005). Hepatitis C virus nonstructural protein $5 \mathrm{~A}$ (NS5A) is an RNA-binding protein. J. Biol. Chem. 280, 36417-36428.

Icard, V., Diaz, O., Scholtes, C., PerrinCocon, L., Ramiere, C., Bartenschlager, R., Penin, F., Lotteau, V., and Andre, P. (2009). Secretion of hepatitis $\mathrm{C}$ virus envelope glycoproteins depends on assembly of apolipoprotein B positive lipoproteins. PLoS ONE 4, e4233. doi:10.1371/journal.pone.0004233

Ishii, K., Murakami, K., Hmwe, S. S., Zhang, B., Li, J., Shirakura, M., Morikawa, K., Suzuki, R., Miyamura, T., Wakita, T., and Suzuki, T. (2008). Trans-encapsidation of hepatitis $\mathrm{C}$ virus subgenomic replicon RNA with viral structure proteins. Biochem. Biophys. Res. Commun. 371, 446-450.

Ito, T., and Lai, M. M. (1999). An internal polypyrimidine-tractbinding protein-binding site in the hepatitis C virus RNA attenuates translation, which is relieved by the 3'-untranslated sequence. Virology 254, 288-296.

Jiang, J., and Luo, G. (2009). Apolipoprotein E but not B is required for the formation of infectious hepatitis $\mathrm{C}$ virus particles. $J$. Virol. 83, 12680-12691.

Jirasko, V., Montserret, R., Appel, N., Janvier, A., Eustachi, L., Brohm, C., Steinmann, E., Pietschmann, T., Penin, F., and Bartenschlager, R. (2008). Structural and functional characterization of nonstructural protein 2 for its role in hepatitis C virus assembly. J. Biol. Chem. 283, 28546-28562.

Jirasko, V., Montserret, R., Lee, J. Y., Gouttenoire, J., Moradpour, D., Penin, F., and Bartenschlager, R. (2010). Structural and functional studies of nonstructural protein 2 of the hepatitis $\mathrm{C}$ virus reveal its key role as organizer of virion assembly. PLoS Pathog. 6, e1001233. doi:10.1371/journal.ppat.1001233

Jones, C. T., Murray, C. L., Eastman, D. K., Tassello, J., and Rice, C. M. (2007). Hepatitis C virus p7 and NS2 proteins are essential for production of infectious virus. J. Virol 81, 8374-8383.

Kapadia, S. B., Barth, H., Baumert, T. Mckeating, J. A., and Chisari, F. V. (2007). Initiation of hepatitis C virus infection is dependent on cholesterol and cooperativity between CD81 and scavenger receptor B type I. J. Virol. 81, 374-383.

Klein, K. C., Dellos, S. R., and Lingappa, J. R. (2005). Identification of residues in the hepatitis $C$ virus core protein that are critical for capsid assembly in a cell-free system. $J$. Virol. 79, 6814-6826.

Klein, K. C., Polyak, S. J., and Lingappa, J. R. (2004). Unique features of hepatitis $\mathrm{C}$ virus capsid formation revealed by de novo cell-free assembly. J. Virol. 78, 9257-9269.

Kopp, M., Murray, C. L., Jones, C. T., and Rice, C. M. (2010). Genetic analysis of the carboxy-terminal region of the hepatitis $\mathrm{C}$ virus core protein. $J$. Virol. 84, 1666-1673.

Kunkel, M., Lorinczi, M., Rijnbrand, R., Lemon, S. M., and Watowich, S. J. (2001). Self-assembly of nucleocapsid-like particles from recombinant hepatitis $\mathrm{C}$ virus core protein. J. Virol. 75, 2119-2129.

Kushima, Y., Wakita, T., and Hijikata, M. (2010). A disulfide-bonded dimer of the core protein of hepatitis $\mathrm{C}$ virus is important for virus-like particle production. J. Virol. 84, 9118-9127.

Lindenbach, B. D., Evans, M. J., Syder, A. J., Wolk, B., Tellinghuisen, T. L. Liu, C. C., Maruyama, T., Hynes, R. O., Burton, D. R., Mckeating, J. A., and Rice, C. M. (2005). Complete replication of hepatitis $C$ virus in cell culture. Science 309, 623-626.

Lindenbach, B. D., Meuleman, P., Ploss, A., Vanwolleghem, T., Syder, A. J., Mckeating, J. A., Lanford, R. E., Feinstone, S. M., Major, M. E., LerouxRoels, G., and Rice, C. M. (2006). Cell culture-grown hepatitis $\mathrm{C}$ virus is infectious in vivo and can be recultured in vitro. Proc. Natl. Acad. Sci. U.S.A. 103, 3805-3809.

Ma, Y., Anantpadma, M., Timpe, J. M., Shanmugam, S., Singh, S. M. Lemon, S. M., and Yi, M. (2011). Hepatitis C virus NS2 protein serves as a scaffold for virus assembly by interacting with both structural and nonstructural proteins. J. Virol. 85 , 86-97.
Ma, Y., Yates, J., Liang, Y., Lemon, S. M., and Yi, M. (2008). NS3 helicase domains involved in infectious intracellular hepatitis $\mathrm{C}$ virus particle assembly. J. Virol. 82, 7624-7639.

Maillard, P., Huby, T., Andreo, U., Moreau, M., Chapman, J., and Budkowska, A. (2006). The interaction of natural hepatitis $\mathrm{C}$ virus with human scavenger receptor SR$\mathrm{BI} / \mathrm{Cla} 1$ is mediated by ApoBcontaining lipoproteins. FASEB J. 20, 735-737.

Majeau, N., Gagne, V., Boivin, A., Bolduc, M., Majeau, J.-A., Ouellet, D., and Leclerc, D. (2004). The N-terminal half of the core protein of hepatitis $\mathrm{C}$ virus is sufficient for nucleocapsid formation. J. Gen. Virol. 85, 971-981.

Masaki, T., Suzuki, R., Murakami, K., Aizaki, H., Ishii, K., Murayama, A. Date, T., Matsuura, Y., Miyamura, T., Wakita, T., and Suzuki, T. (2008). Interaction of hepatitis $C$ virus nonstructural protein $5 \mathrm{~A}$ with core protein is critical for the production of infectious virus particles. J. Virol. 82, 7964-7976.

Masaki, T., Suzuki, R., Saeed, M., Mori, K.-I., Matsuda, M., Aizaki, H., Ishii K., Maki, N., Miyamura, T., Matsuura, Y., Wakita, T., and Suzuki, T. (2010). Production of infectious hepatitis $\mathrm{C}$ virus by using RNA polymerase I-mediated transcription. $J$. Virol. 84, 5824-5835.

McLauchlan, J., Lemberg, M. K., Hope, G., and Martoglio, B. (2002). Intramembrane proteolysis promotes trafficking of hepatitis $\mathrm{C}$ virus core protein to lipid droplets. $E M B O$ J. 21, 3980-3988.

McMullan, L. K., Grakoui, A., Evans, M. J., Mihalik, K., Puig, M., Branch, A. D., Feinstone, S. M., and Rice, C. M. (2007). Evidence for a functional RNA element in the hepatitis $\mathrm{C}$ virus core gene. Proc. Natl. Acad. Sci. U.S.A. 104, 2879-2884.

Meunier, J.-C., Russell, R. S., Engle, R. E., Faulk, K. N., Purcell, R. H., and Emerson, S. U. (2008). Apolipoprotein $\mathrm{cl}$ association with hepatitis C virus. J. Virol. 82, 9647-9656.

Miyanari, Y., Atsuzawa, K., Usuda, N., Watashi, K., Hishiki, T., Zayas, M., Bartenschlager, R., Wakita, T., Hijikata, M., and Shimotohno, K. (2007). The lipid droplet is an important organelle for hepatitis C virus production. Nat. Cell Biol. 9, 1089-1097.

Moradpour, D., Brass, V., and Penin, F. (2005). Function follows form: the structure of the $\mathrm{N}$-terminal domain of HCV NS5A. Hepatology 42, 732-735. 
Moradpour, D., Wakita, T., Tokushige, K., Carlson, R. I., Krawczynski, K., and Wands, J. R. (1996). Characterization of three novel monoclonal antibodies against hepatitis $\mathrm{C}$ virus core protein. J. Med. Virol. 48, 234-241.

Moriishi, K., Mochizuki, R., Moriya, K., Miyamoto, H., Mori, Y., Abe, T., Murata, S., Tanaka, K., Miyamura, T., Suzuki, T., Koike, K., and Matsuura, Y. (2007). Critical role of PA28gamma in hepatitis C virusassociated steatogenesis and hepatocarcinogenesis. Proc. Natl. Acad. Sci. U.S.A. 104, 1661-1666.

Moriishi, K., Okabayashi, T., Nakai, K., Moriya, K., Koike, K., Murata, S., Chiba, T., Tanaka, K., Suzuki, R., Suzuki, T., Miyamura, T., and Matsuura, Y. (2003). Proteasome activator PA28gamma-dependent nuclear retention and degradation of hepatitis C virus core protein. J. Virol. 77, 10237-10249.

Moriishi, K., Shoji, I., Mori, Y., Suzuki, R., Suzuki, T., Kataoka, C., and Matsuura, Y. (2010). Involvement of PA28gamma in the propagation of hepatitis C virus. Hepatology 52, 411-420.

Moriya, K., Fujie, H., Shintani, Y., Yotsuyanagi, H., Tsutsumi, T., Ishibashi, K., Matsuura, Y., Kimura, S., Miyamura, T., and Koike, K. (1998). The core protein of hepatitis C virus induces hepatocellular carcinoma in transgenic mice. Nat. Med. 4, 1065-1067.

Murray, C. L., Jones, C. T., Tassello, J., and Rice, C. M. (2007). Alanine scanning of the hepatitis $C$ virus core protein reveals numerous residues essential for production of infectious virus. J. Virol. 81, 10220-10231.

Nakai, K., Okamoto, T., KimuraSomeya, T., Ishii, K., Lim, C. K., Tani, H., Matsuo, E., Abe, T., Mori, Y., Suzuki, T., Miyamura, T., Nunberg, J. H., Moriishi, K., and Matsuura, Y. (2006). Oligomerization of hepatitis $\mathrm{C}$ virus core protein is crucial for interaction with the cytoplasmic domain of E1 envelope protein. J. Virol. 80, 11265-11273.

Nielsen, S. U., Bassendine, M. F., Burt, A. D., Martin, C., Pumeechockchai, W., and Toms, G. L. (2006). Association between hepatitis $\mathrm{C}$ virus and very-low-density lipoprotein (VLDL)/LDL analyzed in iodixanol density gradients. $J$. Virol. 80, 2418-2428.

Ogawa, K., Hishiki, T., Shimizu, Y., Funami, K., Sugiyama, K., Miyanari, Y., and Shimotohno, K. (2009). Hepatitis C virus utilizes lipid droplet for production of infectious virus. Proc. Jpn. Acad. Ser. B Phys. Biol. Sci. 85, 217-228.

Ogino, T., Fukuda, H., Imajoh-Ohmi, S., Kohara, M., and Nomoto, A. (2004). Membrane binding properties and terminal residues of the mature hepatitis $\mathrm{C}$ virus capsid protein in insect cells. J. Virol. 78, 11766-11777.

Okamoto, K., Mori, Y., Komoda, Y., Okamoto, T., Okochi, M., Takeda, M., Suzuki, T., Moriishi, K., and Matsuura, Y. (2008). Intramembrane processing by signal peptide peptidase regulates the membrane localization of hepatitis $\mathrm{C}$ virus core protein and viral propagation. J. Virol. 82, 8349-8361.

Okamoto, K., Moriishi, K., Miyamura, T., and Matsuura, Y. (2004). Intramembrane proteolysis and endoplasmic reticulum retention of hepatitis C virus core protein. $J$. Virol. 78, 6370-6380.

Op De Beeck, A., Voisset, C., Bartosch, B., Ciczora, Y., Cocquerel, L., Keck, Z., Foung, S., Cosset, F.-L., and Dubuisson, J. (2004). Characterization of functional hepatitis $\mathrm{C}$ virus envelope glycoproteins. J. Virol. 78, 2994-3002.

Owen, D. M., Huang, H., Ye, J., and Gale, M. Jr. (2009). Apolipoprotein E on hepatitis $\mathrm{C}$ virion facilitates infection through interaction with lowdensity lipoprotein receptor. Virology 394, 99-108.

Pawlotsky, J. M. (2006). Hepatitis C virus population dynamics during infection. Curr. Top. Microbiol. Immunol. 299, 261-284.

Phan, T., Beran, R. K. F., Peters, C., Lorenz, I. C., and Lindenbach, B. D. (2009). Hepatitis C virus NS2 protein contributes to virus particle assembly via opposing epistatic interactions with the E1-E2 glycoprotein and NS3-NS4A enzyme complexes. J. Virol. 83, 8379-8395.

Phan, T., Kohlway, A., Dimberu, P., Pyle, A. M., and Lindenbach, B. D. (2011). The acidic domain of hepatitis C virus NS4A contributes to RNA replication and virus particle assembly. J. Virol. 85, 1193-1204.

Pietschmann, T., Kaul, A., Koutsoudakis, G., Shavinskaya, A., Kallis, S., Steinmann, E., Abid, K., Negro, F., Dreux, M., Cosset, F.-L., and Bartenschlager, R. (2006). Construction and characterization of infectious intragenotypic and intergenotypic hepatitis $\mathrm{C}$ virus chimeras. Proc. Natl. Acad. Sci. U.S.A. 103, 7408-7413.

Popescu, C.-I., Callens, N., Trinel, D., Roingeard, P., Moradpour, D., Descamps, V., Duverlie, G., Penin, F., Heliot, L., Rouille, Y., and
Dubuisson, J. (2011). NS2 protein of hepatitis $C$ virus interacts with structural and nonstructural proteins towards virus assembly. PLoS Pathog. 7, e1001278. doi:10.1371/journal.ppat.1001278

Rouille, Y., Helle, F., Delgrange, D. Roingeard, P., Voisset, C., Blanchard, E., Belouzard, S., Mckeating, J., Patel, A. H., Maertens, G., Wakita, T., Wychowski, C., and Dubuisson, J. (2006). Subcellular localization of hepatitis $\mathrm{C}$ virus structural proteins in a cell culture system that efficiently replicates the virus. J. Virol. 80, 2832-2841.

Saeed, M., Suzuki, R., Watanabe, N. Masaki, T., Tomonaga, M., Muhammad, A., Kato, T., Matsuura, Y., Watanabe, H., Wakita, T., and Suzuki, T. (2011). Role of the endoplasmic reticulum-associated degradation (ERAD) pathway in degradation of hepatitis $C$ virus envelope proteins and production of virus particles. J. Biol. Chem. 286, 37264-37273.

Sakai, A., Claire, M. S., Faulk, K., Govindarajan, S., Emerson, S. U., Purcell, R. H., and Bukh, J. (2003). The p7 polypeptide of hepatitis $\mathrm{C}$ virus is critical for infectivity and contains functionally important genotype-specific sequences. Proc. Natl. Acad. Sci. U.S.A. 100, 11646-11651.

Schwer, B., Ren, S., Pietschmann, T., Kartenbeck, J., Kaehlcke, K., Bartenschlager, R., Yen, T. S. B., and Ott, M. (2004). Targeting of hepatitis $\mathrm{C}$ virus core protein to mitochondria through a novel C-terminal localization motif. J. Virol. 78, 7958-7968.

Shavinskaya, A., Boulant, S., Penin, F. Mclauchlan, J., and Bartenschlager, R. (2007). The lipid droplet binding domain of hepatitis $C$ virus core protein is a major determinant for efficient virus assembly. J. Biol. Chem. 282, 37158-37169.

Shi, S. T., Polyak, S. J., Tu, H., Taylor, D. R., Gretch, D. R., and Lai, M. M. C. (2002). Hepatitis C virus NS5A colocalizes with the core protein on lipid droplets and interacts with apolipoproteins. Virology 292, 198-210.

Shirakura, M., Murakami, K., Ichimura, T., Suzuki, R., Shimoji, T., Fukuda, K., Abe, K., Sato, S., Fukasawa, M. Yamakawa, Y., Nishijima, M., Moriishi, K., Matsuura, Y., Wakita, T., Suzuki, T., Howley, P. M., Miyamura, T., and Shoji, I. (2007). E6AP ubiquitin ligase mediates ubiquitylation and degradation of hepatitis $\mathrm{C}$ virus core protein. J. Virol. 81, 1174-1185.
Simmonds, P. (1996). Virology of hepatitis $\mathrm{C}$ virus. Clin. Ther. 18 Suppl B, 9-36.

Stapleford, K. A., and Lindenbach, B. D. (2011). Hepatitis C virus NS2 coordinates virus particle assembly through physical interactions with the E1-E2 glycoprotein and NS3NS4A enzyme complexes. J. Virol. 85, 1706-1717.

Steinmann, E., Brohm, C., Kallis, S., Bartenschlager, R., and Pietschmann, T. (2008). Efficient trans-encapsidation of hepatitis C virus RNAs into infectious virus-like particles. J. Virol. 82, 7034-7046.

Steinmann, E., Penin, F., Kallis, S., Patel, A. H., Bartenschlager, R., and Pietschmann, T. (2007). Hepatitis $\mathrm{C}$ virus $\mathrm{p} 7$ protein is crucial for assembly and release of infectious virions. PLoS Pathog. 3, e103. doi:10.1371/journal.ppat.0030103

Suzuki, R., Moriishi, K., Fukuda, K., Shirakura, M., Ishii, K., Shoji, I., Wakita, T., Miyamura, T., Matsuura, Y., and Suzuki, T. (2009). Proteasomal turnover of hepatitis $\mathrm{C}$ virus core protein is regulated by two distinct mechanisms: a ubiquitin-dependent mechanism and ubiquitin-independent but PA28gamma-dependent mechanism. J. Virol. 83, 2389-2392.

Suzuki, R., Sakamoto, S., Tsutsumi, T., Rikimaru, A., Tanaka, K., Shimoike, T., Moriishi, K., Iwasaki, T., Mizumoto, K., Matsuura, Y., Miyamura, T., and Suzuki, T. (2005). Molecular determinants for subcellular localization of hepatitis $\mathrm{C}$ virus core protein. J. Virol. 79, 1271-1281.

Suzuki, R., Tamura, K., Li, J., Ishii, K., Matsuura, Y., Miyamura, T., and Suzuki, T. (2001). Ubiquitinmediated degradation of hepatitis $\mathrm{C}$ virus core protein is regulated by processing at its carboxyl terminus. Virology 280, 301-309.

Tanaka, T., Kato, N., Cho, M. J., and Shimotohno, K. (1995). A novel sequence found at the 3' terminus of hepatitis $\mathrm{C}$ virus genome. Biochem. Biophys. Res. Commun. 215, 744-749.

Targett-Adams, P., Hope, G., Boulant, S., and Mclauchlan, J. (2008). Maturation of hepatitis $\mathrm{C}$ virus core protein by signal peptide peptidase is required for virus production. J. Biol. Chem. 283, 16850-16859.

Tellinghuisen, T. L., Foss, K. L., and Treadaway, J. (2008). Regulation of hepatitis $\mathrm{C}$ virion production via phosphorylation of the NS5A protein. PLoS Pathog. 4, e1000032. doi:10.1371/journal.ppat.1000032 
Tellinghuisen, T. L., Marcotrigiano, J., and Rice, C. M. (2005). Structure of the zinc-binding domain of an essential component of the hepatitis C virus replicase. Nature 435, 374-379.

Thomssen, R., Bonk, S., Propfe, C., Heermann, K. H., Kochel, H. G., and Uy, A. (1992). Association of hepatitis $C$ virus in human sera with beta-lipoprotein. Med. Microbiol. Immunol. 181, 293-300.

Tsukiyama-Kohara, K., Iizuka, N., Kohara, M., and Nomoto, A. (1992). Internal ribosome entry site within hepatitis C virus RNA. J. Virol. 66, 1476-1483.

Vieyres, G., Thomas, X., Descamps, V., Duverlie, G., Patel, A. H., and Dubuisson, J. (2010). Characterization of the envelope glycoproteins associated with infectious hepatitis C virus. J. Virol. 84, 10159-10168.

Voisset, C., Lavie, M., Helle, F., Op De Beeck, A., Bilheu, A., BertrandMichel, J., Terce, F., Cocquerel, L., Wychowski, C., Vu-Dac, N., and Dubuisson, J. (2008). Ceramide enrichment of the plasma membrane induces CD81 internalization and inhibits hepatitis $\mathrm{C}$ virus entry. Cell. Microbiol. 10, 606-617.

Wakita, T., Pietschmann, T., Kato, T., Date, T., Miyamoto, M., Zhao, Z.
Murthy, K., Habermann, A., Krausslich, H.-G., Mizokami, M., Bartenschlager, R., and Liang, T. J. (2005). Production of infectious hepatitis $\mathrm{C}$ virus in tissue culture from a cloned viral genome. Nat. Med. 11, 791-796.

Wang, C., Sarnow, P., and Siddiqui, A. (1993). Translation of human hepatitis $\mathrm{C}$ virus RNA in cultured cells is mediated by an internal ribosome-binding mechanism. J. Virol. 67, 3338-3344.

Wasley, A., and Alter, M. J. (2000). Epidemiology of hepatitis C: geographic differences and temporal trends. Semin. Liver Dis. 20, 1-16.

Wolk, B., Sansonno, D., Krausslich, H. G., Dammacco, F., Rice, C. M., Blum, H. E., and Moradpour, D. (2000). Subcellular localization, stability, and trans-cleavage competence of the hepatitis $\mathrm{C}$ virus NS3-NS4A complex expressed in tetracycline-regulated cell lines. $J$. Virol. 74, 2293-2304.

Wozniak, A. L., Griffin, S., Rowlands, D., Harris, M., Yi, M., Lemon, S. M., and Weinman, S. A. (2010). Intracellular proton conductance of the hepatitis $\mathrm{C}$ virus $\mathrm{p} 7$ protein and its contribution to infectious virus production. PLoS Pathog. 6, e1001087. doi:10.1371/journal.ppat.1001087
Yamamoto, M., Aizaki, H., Fukasawa, M., Teraoka, T., Miyamura T., Wakita, T., and Suzuki, T. (2011). Structural requirements of virion-associated cholesterol for infectivity, buoyant density and apolipoprotein association of hepatitis C virus. J. Gen. Virol. 92, 2082-2087.

Yasui, K., Wakita, T., Tsukiyama-Kohara, K., Funahashi, S. I., Ichikawa, M., Kajita, T., Moradpour, D. Wands, J. R., and Kohara, M (1998). The native form and maturation process of hepatitis C virus core protein. J. Virol. 72, 6048-6055.

Yi, M., and Lemon, S. M. (2003). 3'Nontranslated RNA signals required for replication of hepatitis $\mathrm{C}$ virus RNA. J. Virol. 77, 3557-3568.

Yi, M., Ma, Y., Yates, J., and Lemon, S. M. (2007). Compensatory mutations in E1, p7, NS2, and NS3 enhance yields of cell culture-infectious intergenotypic chimeric hepatitis $\mathrm{C}$ virus. $J$. Virol. 81, 629-638.

Yi, M., Ma, Y., Yates, J., and Lemon, S. M. (2009). Trans-complementation of an NS2 defect in a late step in hepatitis C virus (HCV) particle assembly and maturation. PLoS Pathog. 5, e1000403. doi:10.1371/journal.ppat. 1000403
Zhong, J., Gastaminza, P., Cheng, G., Kapadia, S., Kato, T., Burton, D. R., Wieland, S. F., Uprichard, S. L., Wakita, T., and Chisari, F. V. (2005). Robust hepatitis $\mathrm{C}$ virus infection in vitro. Proc. Natl. Acad. Sci. U.S.A 102, 9294-9299.

Conflict of Interest Statement: The author declares that the research was conducted in the absence of any commercial or financial relationships that could be construed as a potential conflict of interest.

Received: 16 December 2011; accepted: 23 January 2012; published online: 07 February 2012

Citation: Suzuki T (2012) Morphogenesis of infectious hepatitis $C$ virus particles. Front. Microbio. 3:38. doi: 10.3389/fmicb.2012.00038

This article was submitted to Frontiers in Virology, a specialty of Frontiers in Microbiology.

Copyright (c) 2012 Suzuki. This is an open-access article distributed under the terms of the Creative Commons Attribution Non Commercial License, which permits non-commercial use, distribution, and reproduction in other forums, provided the original authors and source are credited. 